\title{
Interactive comment on "Comparative assessment of GRASP algorithm for a dust event over Granada (Spain) during ChArMEx-ADRIMED 2013 campaign" by Jose Antonio Benavent-Oltra et al.
}

Jose Antonio Benavent-Oltra et al.

jbenavent@ugr.es

Received and published: 18 September 2017

We would like to thank to the editor Dr. Dulac for their constructive and useful comments. The supplement file contains the authors' responses to comments from the editor.

Please also note the supplement to this comment: 